\title{
EFEKTIVITAS BALANCE EXERCISE DAN GAIT TRAINING DALAM MENINGKATKAN KESEIMBANGAN DAN KECEPATAN BERJALAN PADA KASUS STROKE ISKEMIK
}

\author{
Aditya Denny Pratama1, Aisyah Aji Furqonah ${ }^{1}$ \\ ${ }^{1}$ Program Studi Fisioterapi, Program Pendidikan Vokasi, Universitas Indonesia \\ Email : adityadennypratama@gmail.com
}

\begin{abstract}
ABSTRAK
Stroke merupakan hilangnya fungsi otak secara mendadak dan memicu kelumpuhan unilateral yang dapat mengurangi kontrol postur dan keseimbangan sehingga pasien kesulitan untuk berjalan. Tujuan studi kasus ini adalah mengetahui efektivitas balance exercise dan gait training terhadap peningkatan keseimbangan dan kecepatan berjalan pada pasien stroke menggunakan parameter Timed Up and Go Test (TUGT) dan 10 Meter Walk Test (10MWT). Metode yang digunakan adalah evidence-based case report dengan pertanyaan klinis, "Bagaimana efektivitas balance exercise dan gait training terhadap peningkatan keseimbangan dan kecepatan berjalan pada kasus stroke iskemik?" dengan penelusuran bukti pada 3 database, yaitu Pubmed, science direct, dan scopus. Setelah dilakukan 6 kali evaluasi terdapat peningkatan keseimbangan dan kecepatan dimana pada evaluasi pertama didapatkan hasil pengukuran TUGT sebesar 14,14 detik, self selected velocity $0,63 \mathrm{~m} / \mathrm{s}$ dan fast velocity $0,66 \mathrm{~m} / \mathrm{s}$. Pada evaluasi keenam didapatkan hasil sebesar 09,50 detik, self selected velocity $1,34 \mathrm{~m} / \mathrm{s}$ dan fast velocity $1,40 \mathrm{~m} / \mathrm{s}$ sehingga dapat disimpulkan bahwa balance exercise dan gait training efektif dalam meningkatkan keseimbangan dan kecepatan berjalan pada pasien stroke dengan nilai minimal detectable change (MDC) TUGT sebesar 2,9 detik dan 10MWT pada self selected velocity sebesar $0,18 \mathrm{~m} / \mathrm{s}$ dan fast velocity sebesar $0,13 \mathrm{~m} / \mathrm{s}$ serta nilai minimally clinically important difference (MCID) TUGT sebesar 3,4 detik dan 10MWT sebesar $0,16 \mathrm{~m} / \mathrm{s}$.
\end{abstract}

Kata kunci: Stroke; Stroke ischemic; Balance exercise; Gait training

\begin{abstract}
Stroke is a sudden loss of brain function and triggers unilateral paralysis which can reduce posture and balance control so that the patient has difficulty walking. The purpose of this case study was to determine the effectiveness of balance exercise and gait training on improving balance and gait velocity in stroke patients using the Timed Up and Go Test (TUGT) and 10 Meter Walk Test (10MWT) parameters. The method used is an evidence-based case report with clinical questions, "How is the effectiveness of balance exercise and gait training on improving balance and gait velocity in ischemic stroke cases?" by searching for evidence in 3 databases, namely Pubmed, Science Direct, and Scopus. After 6 evaluations there was an increase in balance and speed where in the first evaluation the results of the TUGT measurement were 14.14 seconds, selfselected velocity $0.63 \mathrm{~m} / \mathrm{s}$ and fast velocity $0.66 \mathrm{~m} / \mathrm{s}$. In the sixth evaluation, the results obtained are 09.50 seconds, self-selected velocity $1.34 \mathrm{~m} / \mathrm{s}$ and fast velocity $1.40 \mathrm{~m} / \mathrm{s}$ so it can be concluded that balance exercise and gait training effective in improving balance and gait velocity in stroke patients with a minimal detectable change (MDC) TUGT is 2.9 seconds and 10MWT at a self-selected velocity is $0.18 \mathrm{~m} / \mathrm{s}$ and a fast velocity is $0.13 \mathrm{~m} / \mathrm{s}$ and a minimally clinically important difference (MCID) TUGT is 3.4 seconds and 10 MWT is $0.16 \mathrm{~m} / \mathrm{s}$.
\end{abstract}

Keywords: Stroke; Stroke ischemic; Balance exercise; Gait training

\section{PENDAHULUAN}

Kesadaran masyarakat akan bahaya perilaku sedentari masih sangat rendah hingga saat ini. Hal ini dibuktikan dengan tingginya angka proporsi penduduk Indonesia dengan aktivitas fisik yang kurang, yaitu sebesar 26,1\%. Aktivitas fisik dikategorikan cukup apabila seseorang melakukan latihan fisik atau olahraga minimal selama 30 menit per hari, atau minimal 3-5 hari dalam 
seminggu. Penurunan aktivitas fisik merupakan salah satu faktor risiko terjadinya penyakit kardiovaskular, yaitu penyakit yang disebabkan oleh gangguang fungsi jantung dan pembuluh darah seperti penyakit jantung dan stroke.(Kementerian Kesehatan Republik Indonesia, 2017)

Stroke adalah gangguan fungsional otak baik fokal maupun global yang terjadi secara mendadak dan berlangsung selama 24 jam atau lebih. Stroke disebabkan oleh gangguan aliran darah otak yang menyebabkan terputusnya suplai darah ke otak sehingga jaringan otak menjadi rusak dengan prevalensi stroke di Indonesia mencapai 12,1 per 1000 penduduk dari seluruh populasi. Klasifikasi stroke terbanyak adalah tipe iskemik dengan angka kejadian sekitar $50-85 \%$, dimana pembuluh darah otak mengalami penyumbatan dan tidak mendapatkan pasokan oksigen sehingga terjadi kematian sel atau jaringan otak. Stroke iskemik mencakup transient ischemic attack, stroke-inevaluation, thrombotic stroke, embolic stroke, dan stroke akibat kompresi seperti tumor, abses, dan granuloma (Permatasari, 2020).

Stroke iskemik ditandai dengan kelemahan pada salah satu sisi tubuh yang ditentukan berdasarkan lokasi otak yang lesi sehingga menimbulkan gangguan motorik, kinerja fungsional dan gaya berjalan. Karakteristik stroke iskemik pada ektremitas bawah, yaitu penurunan fungsi sensorik, kelemahan otot, atrofi otot, tonus otot yang lemah, gangguan weight bearing, kontrol postur, koordinasi, keseimbangan, dan ketidakstabilan tungkai bawah yang ditandai dengan deformitas pada ankle, yaitu plantar flexion dan inversion, pola abnormal gait, yaitu initial contact menggunakan jari-jari kaki sehingga mengakibatkan tidak stabilnya fase berjalan, wide base of support dan peningkatan panjang langkah saat berjalan yang memicu adanya penurunan keseimbangan dan kecepatan berjalan (Song et al., 2018). Oleh karena itu dibutuhkan peran fisioterapi dalam upaya promotif, preventif, kuratif, dan rehabilitatif.

Pada dasarnya terdapat berbagai jenis intervensi yang dapat dilakukan pada pasien stroke hemiparesis sesuai dengan problematika yang ditemukan saat pemeriksaan. Salah satu modalitas fisioterapi yang dapat digunakan sebagai penangananan stroke hemiparesis untuk meningkatkan keseimbangan dan kecepatan berjalan adalah balance exercise dan gait training yang diukur menggunakan parameter TUGT dan 10 MWT. TUGT adalah suatu jenis pengukuran yang digunakan untuk mengevaluasi keseimbangan berjalan terkait dengan risiko jatuh pada pasien dengan sensitivitas dan spesifisitas sebesar 87\%. 10MWT adalah ukuran klinis observasional yang dirancang untuk mengevaluasi kecepatan berjalan pasien stroke dengan nilai signifikansi sebesar $\mathrm{p}<0.001$ (Wowiling, Sengkey and Lolombulan, 2016; Andersen and Kristensen, 2019).

Berdasarkan latar belakang diatas maka penulis tertarik untuk mengangkat judul dan melaporkan hasil terkait efektivitas balance exercise dan gait training dalam meningkatkan keseimbangan dan kecepatan berjalan pada kasus stroke iskemik.

\section{METODE PENELITIAN}

Metode penelitian yang digunakan dalam penulisan artikel ini adalah case report study dengan resume kasus dan masalah klinis sebagai berikut :

\section{Resume Kasus}

Seorang pasien berinisial Tn. S.M berusia 57 tahun dengan diagnosa medis hemiparesis sinistra yang disebabkan oleh stroke iskemik. Pasien pertama kali mengalami serangan pada tanggal 18 November 2020 dikarenakan OS kelelahan saat bekerja, lalu OS langsung dibawa ke bidan terdekat dengan hasil pemeriksaan tekanan darah 140/80 mmHg. OS hanya diberikan vitamin dan dianjurkan untuk istirahat yang cukup.

Lalu keesokan harinya, OS ditemukan oleh anaknya dalam keadaan kaku dan OS sudah tidak mampu menggerakan badannya. OS langsung dibawa ke puskemas terdekat dan langsung diberi 
rujukan ke rumah sakit Anna Bekasi. Pada tanggal 20 November 2020 OS datang ke RS Anna dengan kondisi bibir sudah miring ke kiri. Setelah dilakukan pemeriksaan, tekanan darah OS 145/80 mmHg dan dokter mencurigai bahwa OS mengalami gejala stroke. Oleh karena itu, OS disarankan untuk melakukan pemeriksaan CT Scan. Kemudian, pada tanggal 21 November 2020 OS melakukan pemeriksaan $C T$ Scan dengan hasil adanya infark pada basal ganglia dan periventrikel lateralis kanan dan OS dirawat selama satu minggu. OS sudah menjalani fisioterapi kurang lebih tiga bulan dengan frekuensi $2 \mathrm{x} / \mathrm{minggu}$ dan diberikan intervensi berupa TENS, infrared dan latihan gerak.

Pada proses pemeriksaan fisioterapi pada tanggal 22 Maret 2021, didapatkan problematika fisioterapi berupa kelemahan otot ekstremitas atas dan bawah sisi sinistra, hipotonus pada sisi sinistra, defisit sensoris pada sisi sinistra, gangguan keseimbangan dan kecepatan berjalan yang didapat dari hasil pemeriksaan TUGT dan 10MWT yaitu 18,86 detik, kecepatan berjalan self selected velocity $0,49 \mathrm{~m} / \mathrm{s}$ dan fast velocity $0,53 \mathrm{~m} / \mathrm{s}$.

\section{Masalah Klinis}

Terdapat berbagai macam masalah klinis yang timbul akibat stroke. Fisioterapi menjadi salah satu upaya untuk mengatasi problematika yang muncul. Masalah fisioterapi yang ditemukan diantaranya kelemahan otot, hipotonus, defisit sensoris, dan gangguan keseimbangan berjalan. Berdasarkan permasalahan tersebut, masalah fisioterapi yang penulis angkat pada studi kasus ini adalah gangguan keseimbangan dan kecepatan berjalan dengan intervensi yang diberikan, yaitu balance exercise dan gait training. Sehingga dapat diajukan pertanyaan klinis sebagai berikut : "Bagaimana pengaruh pemberian balance exercise dan gait training terhadap peningkatan keseimbangan dan kecepatan berjalan pada kasus stroke iskemik?"

\section{Metode Penelusuran}

Untuk menjawab masalah klinis, dilakukan penelusuran kepustakaan secara online menggunakan instrumen pencarian Pubmed, science direct, dan scopus. Kata kunci yang digunakan adalah stroke, stroke ischemic, balance exercise, dan gait training dengan menggunakan batasan (limit): studi yang dilakukan pada manusia, publikasi Bahasa indonesia dan inggris, kata kunci terdapat pada judul atau abstrak, serta jenis publikasi berupa uji klinis, uji klinis terandomisasi, meta - analisis, dan review.

\section{HASIL PENELITIAN}

Dalam studi kasus ini penulis membahas mengenai kondisi pasien yang berinisial Tn. S.M dengan diagnosa stroke hemiparesis sinistra yang disebabkan oleh stroke iskemik. Dari hasil pemeriksaan ditemukan beberapa permasalahan, yaitu kelemahan otot pada ekstremitas atas dan bawah pada sisi sinistra, hipotonus pada sisi sinistra, defisit sensoris pada sisi sinistra, gangguan keseimbangan jalan, dan penurunan fungsi ADL dengan ketergantungan moderate (sedang).

Pada kasus ini pemberian intervensi fisioterapi dapat dilakukan dengan banyak cara sesuai dengan permasalahan yang ditemukan dari hasil pemeriksaan. Oleh karena itu, penulis menggunakan intervensi berupa balance exercise dan gait training.

Dari seluruh rangkaian intervensi yang telah diberikan, didapatkan perubahan hasil pengukuran keseimbangan dan kecepatan berjalan yang diukur dengan TUGT dan 10MWT setelah dilakukan enam kali evaluasi sesuai pada grafik dibawah ini.

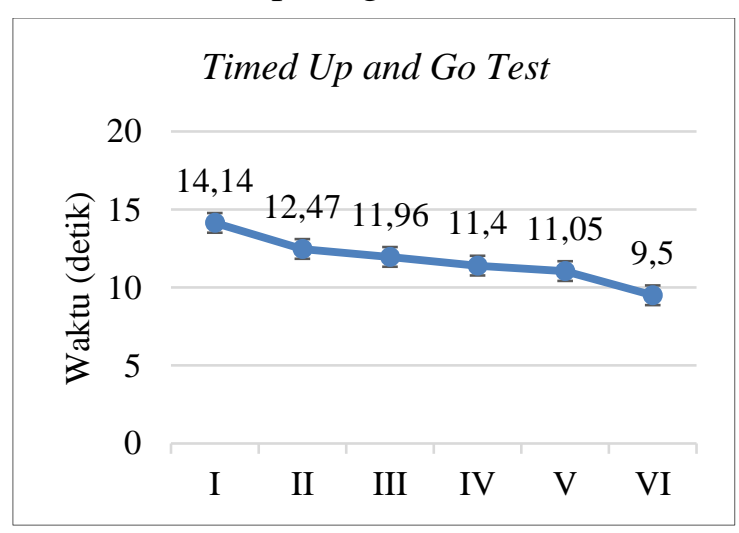

Grafik 1. Hasil Evaluasi TUGT 
Berdasarkan grafik diatas menujukkan adanya peningkatan keseimbangan dan kecepatan berjalan yang diukur dengan TUGT dari evaluasi pertama hingga evaluasi keenam. Pada evaluasi TUGT pertama didapatkan hasil perhitungan waktu sebesar 14,14 detik yang menginterpretasikan adanya risiko jatuh ringan dan pada evaluasi keenam didapatkan perubahan hasil perhitungan waktu menjadi 09,50 detik yang menginterpretasikan keseimbangan pasien dengan kemandirian penuh.

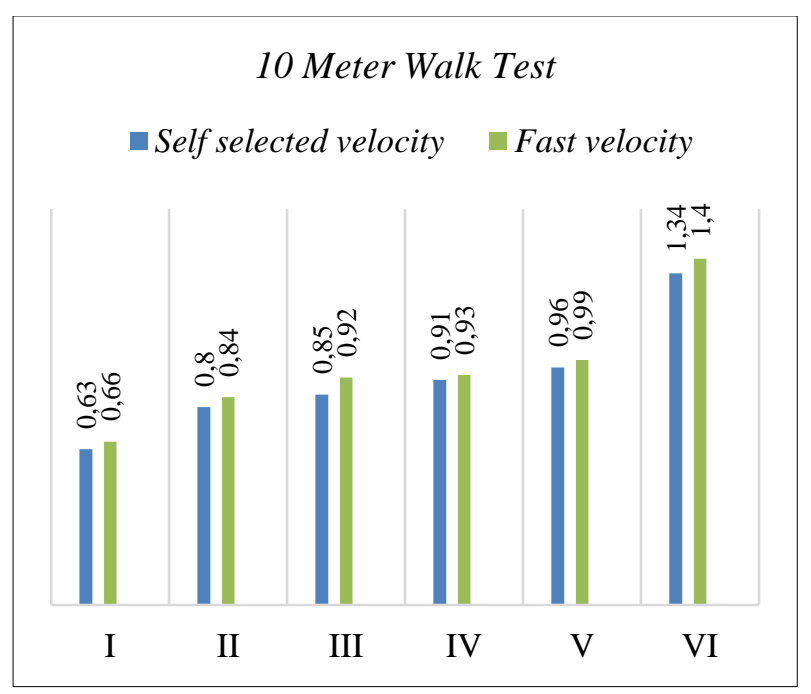

Grafik 2. Hasil Evaluasi 10MWT

Pada evaluasi 10MWT pertama didapatkan self selected velocity sebesar 0,63 $\mathrm{m} / \mathrm{s}$ dan pada evaluasi keenam didapatkan peningkatan kecepatan berjalan menjadi 1,34 $\mathrm{m} / \mathrm{s}$. Selain itu juga didapatkan hasil pengukuran fast velocity, yaitu pada evaluasi pertama didapatkan kecepatan berjalan sebesar $0,66 \mathrm{~m} / \mathrm{s}$ dan pada evaluasi keenam didapatkan peningkatan kecepatan berjalan menjadi 1,40 $\mathrm{m} / \mathrm{s}$. Berdasarkan evaluasi tersebut dapat disimpulkan bahwa kedua parameter tersebut mengalami peningkatan hasil yang signifikan jika dilihat dari evaluasi pertama sampai dengan evaluasi keenam.

\section{PEMBAHASAN}

Penulis mengangkat studi kasus pada lakilaki berusia 57 tahun dengan diagnosa medis hemiparesis sinistra dengan dilakukan pemeriksaan keseimbangan dan kecepatan berjalan dengan parameter TUGT dan 10MWT. Berdasarkan hasil pemeriksaan, intervensi yang diberikan adalah balance exercise dan gait training. Balance exercise yang diberikan berupa single leg stand, stepping exercise, dan ball training dengan dosis 10 kali repetisi dan hold time 10 detik.

Single leg stand ditujukan untuk meningkatkan proprioseptif guna melatih keseimbangan. Prinsip dari latihan ini adalah mempertahankan posisi tegak lurus dengan satu kaki tanpa bantuan untuk menciptakan keseimbangan serta koordinasi postur tubuh yang baik.

Menurut Bambang et al.(Munawarah et al., 2017b) dalam penelitiannya yang menyatakan bahwa pemberian active one leg standing efektif untuk meningkatkan keseimbangan dan fungsional berjalan pada pasien. Hal ini disebabkan salah satu tungkai mengalami proses pembebanan sehingga akan mengaktivasi otot-otot tungkai, pelvis dan trunk untuk lebih aktif berkontraksi dan menyiapkan kekuatan saat berlangsungnya gerakan one leg standing.

Hal tersebut juga didukung oleh beberapa faktor, pertama, adanya aktivasi otot tungkai dan otot-otot postural yang digunakan saat menumpu sehingga mampu meningkatkan kemampuan dalam mengendalikan posisi tubuh untuk tetap seimbang pada saat mengalami perubahan keseimbangan dalam melakukan suatu gerakan atau disebut anticipatory postural adjustment. Kedua, aktivasi otot-otot tungkai dalam berkontraksi untuk membentuk stabilisasi sebagai tumpuan sebab teraktivasinya otot-otot tungkai saat menumpu. Hal ini akan berpengaruh terhadap proses berjalan dan perpindahan beban tubuh saat berjalan yang akan terjadi dengan baik. Ketiga, meningkatkan kemampuan ankle strategy sebagai salah satu reaksi tubuh dalam mempertahankan keseimbangan sehingga memungkinkan tubuh untuk mempersiapkan kontrol yang optimal saat perubahan gerak selama aktivitas fungsional berlangsung. Keempat, meningkatnya kemampuan reciprocal activity dari otot quadriceps dan hamstring 
yang mampu bekerjasama membentuk kontraksi yang tepat saat terjadi perubahan keseimbangan. Kelima, meningkatkan kekuatan ekstensor hip dan pelvis sehingga tungkai akan stabil saat digunakan untuk menumpu (Munawarah et al., 2017a).

Stepping exercise bertujuan untuk meningkatkan kekuatan pada $m$. gastrocnemius, $m$. tibialis anterior, $m$. hamstring, m. quadriceps, otot-otot ekstensor trunk, dan $m$. abdominal dimana otot-otot tersebut bertujuan untuk menyangga tubuh dari adanya keterbatasan stabilitas sehingga latihan ini akan meningkatkan kestabilan tubuh saat melakukan gerakan pada pusat gravitasi dalam posisi anteroposterior dan mediolateral. Hal tersebut sejalan dengan penelitian yang dilakukan oleh George Hornbi et al (Hornby et al., 2020) yang menyatakan bahwa stepping exercise memberikan perubahan yang signifikan pada peningkatan kemampuan berjalan dan gait simetry sehingga mampu meningkatkan keseimbangan berjalan dan kemampuan beraktifitas pada pasien post stroke dimana latihan ini berhubungan erat dengan fungsi eksekutif, yang melibatkan lobus frontal, termasuk fungsi kognitif yang lebih tinggi seperti kontrol penghambatan, memori kerja, dan fleksibilitas kognitif. sehingga mampu meningkatkan keseimbangan pada pasien stroke.

Ball training berupa latihan menendang bola yang dilakukan pada permukaan lantai yang kasar. Latihan ini merupakan program pelatihan keseimbangan yang ditujukan untuk meningkatkan kepercayaan diri dalam kontrol keseimbangan sehingga mengurangi rasa takut akan jatuh, meningkatkan kecepatan dalam berjalan, dan kemampuan dalam melakukan aktivitas dalam kehidupan sehari-hari (Hofheinz, Mibs and Elsner, 2016). Peningkatan keseimbangan dapat terjadi setelah diberikan latihan ini sebab adanya integrasi kompleks antara sistem sensoris (visual, vestibular, somatosensori) dan motorik dengan regulasi oleh sistem saraf pusat dalam menjaga keseimbangan kerja sendi ketika tubuh bergerak (Sativani, 2019).

Hal tersebut sejalan dengan penelitian yang dilakukan oleh Yan-Ci Liu et al (Liu et $a l .$, 2017) dalam penelitiaannya yang menyatakan bahwa pemberian dual task training menunjukkan peningkatan dalam gait performance (gait speed, stride length, DTC-speed) yang disertai dengan adanya peningkatan dalam keseimbangan dan kognitif. Hal ini dapat terjadi karena dalam melakukan dual-task dibutuhkan kemampuan dalam memfokuskan keseimbangan dari pergerakan tubuh saat mengeksekusi pergerakan motorik. Selain itu, saat dilakukannya latihan ini akan banyak terjadi gerakan yang menyebabkan terjadinya gesekan antara telapak kaki dan permukaan lantai yang kasar sehingga hal ini bisa meningkatkan stimulasi taktil guna meningkatkan sensibilitas dan kontrol postural yang baik, melibatkan interaksi yang kompleks antara visual, somatosensori dan sistem vestibular yang mengontrol hubungan antara segmen tubuh yang berbeda, sehubungan dengan gravitasi, tubuh dan lingkungan.

Intervensi selanjutnya adalah gait training yang diberikan dengan dosis 30 menit/sesi latihan. Gait training merupakan suatu latihan keseimbangan dan koordinasi yang bertujuan untuk mengoptimalkan kinerja dan pola berjalan. Hal tersebut sejalan dengan penelitian yang dilakukan oleh Luis et al.(Mochizuki et al., 2015) pada jurnalnya yang menyatakan bahwa gait training terbukti efektif dan secara signifikan menunjukkan peningkatan kecepatan, jarak, dan keseimbangan berjalan yang disebabkan karena gait training mampu meningkatkan komponen biomekanik gaya berjalan dengan latihan yang dilakukan secara berulang - ulang. Pengulangan tersebut akan memicu munculnya komponen berjalan yang hilang dan memungkinkan pasien untuk mempraktikkan gait cycle secara lengkap yang disertai dengan peningkatan kekuatan otot tungkai bawah yang berkorelasi dengan peningkatan kecepatan berjalan.

\section{KESIMPULAN}

Dapat disimpulkan bahwa pada kasus ini, setelah dilakukan intervensi berupa 
balance exercise dan gait training dengan frekuensi 3 kali/minggu selama 6 minggu, menunjukkan hasil yang signifikan terhadap peningkatan keseimbangan dan kecepatan berjalan pada pasien dengan nilai minimal detectable change (MDC) TUGT sebesar 2,9 detik dan 10MWT pada self selected velocity sebesar $0,18 \mathrm{~m} / \mathrm{s}$ dan fast velocity sebesar 0,13 $\mathrm{m} / \mathrm{s}$ serta nilai minimally clinically important difference (MCID) TUGT sebesar 3,4 detik dan 10MWT sebesar $0,16 \mathrm{~m} / \mathrm{s}$.

\section{DAFTAR PUSTAKA}

Andersen, C. W. and Kristensen, M. T. (2019) 'Performance stability and interrater reliability of culturally adapted 10meter walking test for danes with neurological disorders', Journal of Stroke and Cerebrovascular Diseases, 28(9), pp. 2459-2467. doi: 10.1016/j.jstrokecerebrovasdis.2019.0 6.021 .

Hofheinz, M., Mibs, M. and Elsner, B. (2016) 'Dual task training for improving balance and gait in people with stroke', Cochrane Database of Systematic Reviews, 2016(10). doi: 10.1002/14651858.CD012403.

Hornby, T. G. et al. (2020) 'Contributions of Stepping Intensity and Variability to MObility in Individuals Post Stroke', 50(9), pp. 317-329. doi: 10.1161/STROKEAHA.119.026254. Contributions.

Kementerian Kesehatan Republik Indonesia (2017) 'Panduan Pelaksanaan Gerakan Nusantara Tekan Angka Obesitas.pdf'.

Liu, Y. C. et al. (2017) 'Cognitive and motor dual task gait training improve dual task gait performance after stroke - $\mathrm{z}$ randomized controlled pilot trial', Scientific Reports, 7(1), pp. 1-8. doi: 10.1038/s41598-017-04165-y.

Mochizuki, L. et al. (2015) 'The effect of gait training and exercise programs on gait and balance in post-stroke patients', Medical Express, 2(4), pp. 1-5. doi: 10.5935/medicalexpress.2015.04.01.

Munawarah, M. et al. (2017a) 'Active One Leg
Standing Exercise Lebih Efektif Daripada Contactual Hand Orientating Response ( Chor ) Exercise Untuk Meningkatkan Kemampuan Active One Leg Standing Exercise Was More Efective Than Contactual Hand Orientating Response ( Chor ) Exercise To I', 5(3), pp. 110-117.

Munawarah, M. et al. (2017b) 'Active one leg standing exercise lebih efektif daripada contactual handorientating response exercise untuk meningkatkan kemampuan mobilitas pasien pasca stroke', 5(3), pp. 110-117.

Permatasari, N. (2020) 'Perbandingan stroke non hemoragik dengan gangguan motorik pasien memiliki faktor resiko diabetes melitus dan hipertensi', Jurnal Ilmiah Kesehatan Sandi Husada, 11(1), pp. 298-304. doi: 10.35816/jiskh.v11i1.273.

Sativani, Z. (2019) 'Latihan Keseimbangan dan Stimulasi Somatosensoris Meningkatkan Keseimbangan Statis pada Penderita Diabetes Neuropati', Quality: Jurnal Kesehatan, 13(1), pp. 36-41. doi: 10.36082/qjk.v13i1.54.

Song, S. et al. (2018) 'Effect of horizontal whole-body vibration training on trunk and lower-extremity muscle tone and activation, balance, and gait in a child with cerebral palsy', The American journal of case reports, 19, pp. 1292-1300. doi: 10.12659/AJCR.910468.

Wowiling, P. E., Sengkey, L. S. and Lolombulan, J. H. (2016) 'Pengaruh latihan corestrengthening terhadap stabilitas trunkus dan keseimbangan pasien pasca stroke', Jurnal Biomedik (Jbm), 8(1). doi: 10.35790/jbm.8.1.2016.12334. 